\title{
Model Predictive Control for Micro Grid stabilisation in case of loss of units
}

\author{
Fabrice K/Bidi ${ }^{1}$, Cédric Damour ${ }^{1}$, Dominique Grondin ${ }^{1}$, Mickaël Hilairet ${ }^{2,3}$ (Member, IEEE), Michel Benne $^{1}$
}

\begin{abstract}
This paper presents an energy management system based on a distributed explicit model predictive control. The ability of the energy management system to cope with loss of a unit in an islanded DC micro grid is evaluated. In this study, the DC micro grid is composed with a photovoltaic system, a proton exchange membrane fuel cell, a battery stack and an electrolyzer. The fuel cell and the electrolyzer performance can be affected by many parameters (humidity, temperature, etc.) or auxiliaries control issues. The power of the photovoltaic system can decrease suddenly in case of irradiation loss (weather) or if a part of the photovoltaic surface is hidden. The worst case is the totality loss of one unit (disconnection in failures case). Distributed control can solve this issue by the compensation of the elements between them when a part or the total power capacity of one unit is lost. This work shows the performance of the distributed explicit model predictive control strategy in case of the totality loss of an element.
\end{abstract}

\section{INTRODUCTION}

The ecological transition context has brought the research and industry worlds to develop news energetic system integrated renewable energy sources (RESs). This interest for RESs is due to the greenhouse gas emission and the limitation in the stock of fossil fuel. One way to deal with these environmental issues is the use of RESs like photovoltaic (PV) with a storage system, because of the stochastic aspect of the solar radiation. As storage system, a battery stack can be used. It is a mature technology but the power and the capacity are intrinsically linked and a great capacity requires a large volume. Combine battery with hydrogen storage, electrolyzer and fuel cell (FC) can decorrelate the power and the storage capacity. The FC and electrolyzer current need to have smooth variations to ensure a good health state, so fast variations of the current can be provided by the battery. The combination of many power sources and storage systems is called hybridization. Use hybridization in a Micro Grid (MG) is a good way to deal with stochastic aspects and health state issues. The coordination of the units is performed with an Energy Management System (EMS). The EMS takes into account each unit characteristics and ensures that it is used with respect to its limitations (maximum current, maximum

\footnotetext{
fabrice.kbidi@univ-reunion. fr

${ }^{1} \mathrm{LE}^{2} \mathrm{P}$, Université de la Réunion

15, avenue René Cassin CS 92003 - 97744 Saint-Denis cedex 9

2 FEMTO-ST, Univ. Bourgogne Franche-Comte, CNRS

Rue Thierry Mieg, F-90010 Belfort Cedex, France

3 FCLAB, Univ. Bourgogne Franche-Comte, CNRS

Rue Thierry Mieg, F-90010 Belfort Cedex, France
}

deviation current, etc.).

Model Predictive Control (MPC) can be used for the regulation. In [1], authors use MPC for State of Charge (SoC) regulation in a MG to keep the battery SoC between higher and lower limits and ensure low FC fuel consumption. In [2], authors use passivity based controller to define current reference of each unit and regulate the system voltage.

A decision algorithm can be used to connect or disconnect load or power sources to ensure the voltage regulation of the MG [3]. This method works but causes large variations in the DC bus voltage. In the same way, authors in [4] use decision algorithm to connect or disconnect load to ensure the power balance in the MG.

Another way is the load management system based on load classification [5] or on the resolution of an optimization problem to perform load shedding [6]. But load management does not ensure a good generation and load balance at any time due to the time step.

The power delivered by the FC or the maximum power of the electrolyzer can be affected by degradation processes that can lead to the loss of this unit. That is the reason why the FC and the electrolyzer have current limitations, current variation limits, specifics start/stop conditions and other operating conditions that must be respected [7]-[12]. PV power can also be affected by brutal solar radiation loss (weather change) or degradation/fault (cell faults, module faults or by-pass diode faults [13]). These issues can lead to the loss of the totality of the PV power.

In this paper, the development of an EMS for an hybrid system composed by a Photovoltaic (PV) system, a Proton Exchange Membrane Fuel Cell (PEMFC), a battery stack and an electrolyzer is described and its capacity to cope with the loss of one unit is evaluated. The hydrogen unit current (including fuel cell and electrolyzer currents) and the battery current are optimized by an Distributed Explicit Model Predictive Control (DEMPC). The DEMPC was chosen because of the possibility of using it in real time (explicit solution), the decoupling of the control units (distributed) and its ability to integrate each unit constraints (MPC).

This paper is organized as follows : section 2 details the system modeling, section 3 the EMS design and section 4 simulation results. 


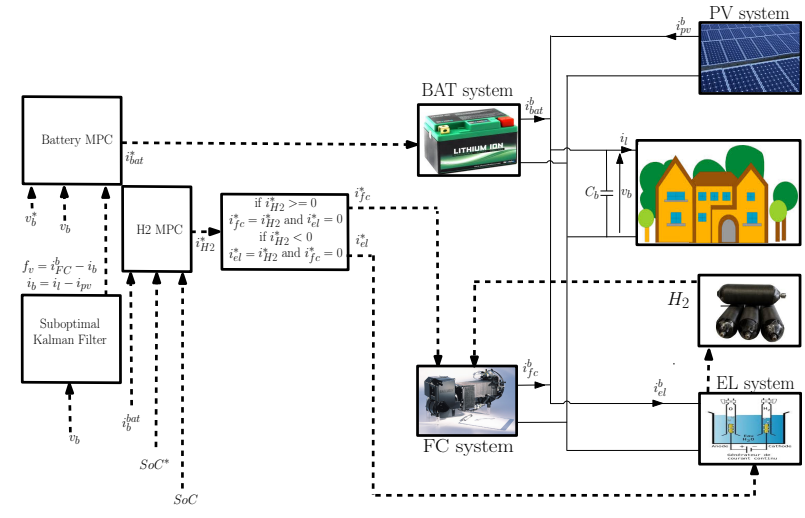

Fig. 1. Micro-grid structure with PVs, Fuel Cell, Electrolyzer, Hydrogen Tank and Batteries

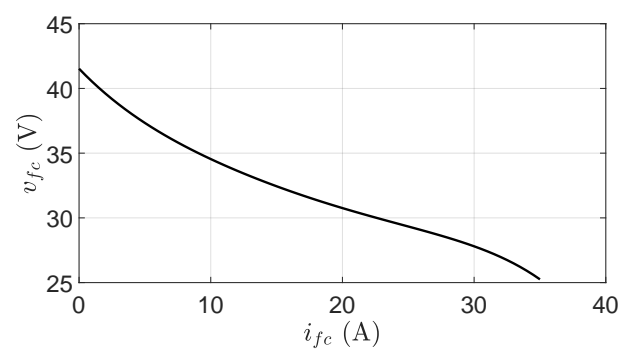

Fig. 2. FC polarization curve

\section{SYSTEM MODELS}

The main characteristics of the simulated system are detailed in Appendix.

\section{A. Photovoltaic System}

The PV power system is approximated with the power equation described in [14]. This method consists of determining the maximum power delivered by the PV system depending on the PV area, the solar radiation, the temperature and the PV panel characteristics.

$$
P_{p v}=\eta_{P V} \eta_{P C} A p v G\left(1+K_{p}\left(T_{n}-T_{c}\right)\right)
$$

with $\eta_{\mathrm{PV}}$ the module efficiency, $\eta_{\mathrm{PC}}$ the efficiency of a Maximum Power Point Tracking (MPPT), Apv the PV area, $K_{p}$ the power temperature factor, $T_{c}$ the cell temperature, $\mathrm{T}_{\mathrm{n}}$ the cell nominal temperature, $\mathrm{G}$ the solar radiation. The cell temperature is a function of the ambient temperature $\mathrm{T}_{\mathrm{amb}}$, the Normal Operating Condition Temperature NOCT and the solar radiation $\mathrm{G}$ [4].

$$
T_{c}=T_{a m b}+\frac{N O C T-20}{800} G
$$

\section{B. Fuel Cell and Electrolyzer}

1) Fuel Cell: The FC behavior is described by a 5th order polynomial fitting curve extracted with experimental data [2] (cf. fig. 2).

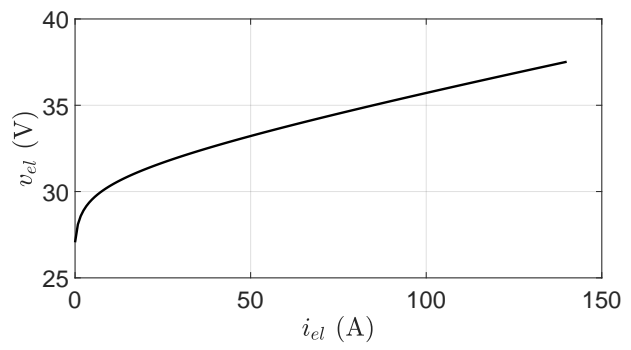

Fig. 3. Electrolyzer polarization curve

2) Electrolyzer: The electrolyzer behavior is described by the equations detailed in [15] (cf. fig. 3). It is an alkaline water electrolyzer with 22 cells of $300 \mathrm{~cm}^{2}$. For simplification, the stack temperature is assumed to be maintained at $70^{\circ} \mathrm{C}$.

\section{Batteries}

The batteries used in this paper are a lithium battery cell, equ. 3-6 detail in [16] describe the battery cell behavior.

$$
\frac{d v_{C p 1_{b a t}}}{d t}(\operatorname{SoC}(t))=
$$

$$
\begin{gathered}
\frac{i_{b a t}}{C_{p 1_{b a t}(S o C(t))}}-\frac{v_{C p 1_{b a t}}}{R_{p 1_{b a t}(S o C(t))} C_{p 1_{b a t}(S o C(t))}} \\
\frac{d v_{C p 2_{b a t}}}{d t}(S o C(t))= \\
\frac{i_{b a t}}{C_{p 2_{b a t}(S o C(t))}}-\frac{v_{C p 2_{b a t}}}{R_{p 1_{b a t}(S o C(t))} C_{p 2_{b a t}(S o C(t))}}
\end{gathered}
$$

$$
\begin{gathered}
v_{b a t}(\operatorname{SoC}(t))= \\
v_{o c(S o C(t))}-v_{C p 1_{b a t}}-v_{C p 2_{b a t}}-i_{b a t} R_{s_{b a t}(S o C(t))} \\
S o C(t)=S o C(t=0)+\frac{\int_{0}^{t} i_{b a t}(\tau) d \tau}{C_{b a t}}
\end{gathered}
$$

\section{DC bus}

The DC bus voltage is determined with the power conservation (cf. eq. 8) (for the DC/DC converter) and Kirchhoff's law.

$$
\begin{gathered}
C_{b} \frac{d v_{b}}{d t}=\sum\left(i_{u n i t}^{b}\right)-i_{l} \\
i_{u n i t} v_{u n i t}=i_{u n i t}^{b} v_{b}
\end{gathered}
$$

with $\mathrm{C}_{\mathrm{b}}$ the bus capacitor, $\mathrm{v}_{\mathrm{b}}$ the $\mathrm{DC}$ bus voltage, $\mathrm{i}_{\mathrm{l}}$ the load current, $i_{\text {unit }}$ is the current of one unit (FC, battery, etc.) and $\mathrm{v}_{\text {unit }}$ the voltage of one unit (FC, battery, etc.), $\mathrm{i}_{\text {unit }}^{\mathrm{b}}$ the current of one unit (FC, battery, etc.) seeing by the DC bus and $v_{u n i t}^{b}$ the voltage of one unit (FC, battery, etc.) seeing by the DC bus.

\section{ENERGY MANAGEMENT SYSTEM}

\section{A. Introduction}

DEMPC is used to compute the battery stack and the hydrogen system current references. It is base on the dynamic equation of the DC bus voltage and the battery 
SoC. FC and electrolyzer are considered as one unit, depending on the same current $\mathrm{i}_{\mathrm{H} 2, \mathrm{k}}$. When it is positive, the FC provides all the current and the electrolyzer current is equal to 0 and vice versa.

The DEMPC system equations is implemented in Matlab with the toolbox Yalmip [17]. Then the Matlab MultiParametric Toolbox [18] with the GUROBI academic solver is used to generate the explicit solution (Barrier method by default). The explicit solution takes the form of a PWA (Piecewise Affine) function. Then, a binary search tree is constructed to reduce the controller computationnal cost.

Currents references are annotated by an exponent * and are considered to be perfectly regulated, specifically $\mathrm{i}_{\text {unit }}=\mathrm{i}_{\text {unit }}^{*}$.

\section{B. Hydrogen system controller}

- Equation and constraints

FC and electrolyzer are used to keep the battery stack SoC close to its reference. The battery current is written with the $\mathrm{H} 2$ current, the PV current and the load current. To linearize the equation system, the currents are written from the battery point of view with the power conservation assumption for the converter $\left(\mathrm{v}_{\text {unit }_{\text {in }}} \mathrm{i}_{\text {unit }_{\text {in }}}=\mathrm{v}_{\text {unit }_{\text {out }}} \mathrm{i}_{\text {unit }_{\text {out }}}\right) \quad: \quad \mathrm{i}_{\text {bat }, \mathrm{k}}=\mathrm{i}_{\mathrm{H} 2, \mathrm{k}}^{\text {bat }}-\mathrm{i}_{\mathrm{l}_{\text {_pv }, \mathrm{k}}}^{\text {bat }}$ (with $\mathrm{i}_{\mathrm{l}_{\text {pp }} \mathrm{bat}}=\mathrm{i}_{\mathrm{l}}^{\text {bat }}-\mathrm{i}_{\mathrm{pv}}^{\mathrm{bat}}$ ). This equation is injected in the discrete-time SoC dynamics equation (Equ. 9) to compute the SoC at each step time and minimize the cost function. The $\mathrm{H} 2$ unit current seen by the battery stack $\mathrm{i}_{\mathrm{H} 2, \mathrm{k}}^{\mathrm{bat} *}$ is the control variable.

$$
S o C_{k}=S o C_{k-1}+\frac{T_{S_{F C}}}{C_{b a t}}\left(i_{H 2, k}^{b a t *}-i_{l_{-} p v, k}^{b a t}\right)
$$

where $\mathrm{i}_{\mathrm{H} 2 *}^{\mathrm{bat}}$ is the $\mathrm{H} 2$ unit current seen by the battery stack, $\mathrm{i}_{\text {l_pv }}^{\text {bat }}$ is the DC bus current seen by the battery stack, SoC is the State of Charge of battery stack, $\mathrm{C}_{\text {bat }}$ is the battery stack capacity. $\mathrm{T}_{\mathrm{S}_{\mathrm{H}}}$ is the sample time of the DEMPC of the $\mathrm{H} 2$ system.

The control law must respect strict constraints like maximum unit current and ramp rate current with respect to the $\mathrm{H} 2$ unit characteristics (maximum power, response time, etc.) to keep them in a proper state of health. In accordance with the $\mathrm{H} 2$ unit characteristics, $\mathrm{i}_{\mathrm{H} 2, \mathrm{k}}$ and $\Delta \mathrm{i}_{\mathrm{H} 2, \mathrm{k}}$ must be maintained between minimum and maximum threshold values. They are also rewritten in the battery stack point of view with the power conservation assumption (Equ. 10 - 14).

$$
\begin{gathered}
i_{H 2, \min , k}^{b a t} \leq i_{H 2, k}^{b a t *} \leq i_{H 2, \max , k}^{b a t} \\
i_{H 2, \min , k}^{b a t}=\frac{v_{H 2, k}\left(i_{H 2, \min }\right)}{v_{b a t, k}} i_{H 2, \min } \\
i_{H 2, \max , k}^{b a t}=\frac{v_{H 2, k}\left(i_{H 2, \max }\right)}{v_{b a t, k}} i_{H 2, \max } \\
-\Delta i_{H 2, \max , k}^{\text {bat }} \leq \Delta i_{H 2, k}^{b a t} \leq \Delta i_{H 2, \max , k}^{b a t} \\
\Delta i_{H 2, \max , k}^{b a t}=\frac{v_{H 2, k}}{v_{b a t, k}} \Delta i_{H 2, \max }
\end{gathered}
$$

where $\mathrm{v}_{\mathrm{H} 2, \mathrm{k}}$ is the $\mathrm{H} 2$ unit voltage, $\mathrm{v}_{\text {bat,k }}$ is the batteries voltage, $\mathrm{i}_{\mathrm{H} 2}$ is the $\mathrm{H} 2$ unit current.

\section{- Cost function}

To keep the SoC battery close to its reference, the cost function is written to minimize the error between $\mathrm{SoC}_{\mathrm{k}}$ and $\mathrm{SoC}^{*}$ (first term), the SoC variation (second term) and the battery current seen by the bus by minimizing the difference between the bus current seen by the battery stack and the $\mathrm{H} 2$ unit current seen by the battery stack (third term) (Equ. 15). This minimization is perform at each horizon time step.

$$
\begin{aligned}
& J\left(S o C_{k}\right)=\min _{i_{H 2}^{b a t}} \sum_{k=0}^{N_{H 2}^{2}}\left[\left(S o C_{k}-S o C^{*}\right)^{2} Q_{r_{-} H 2}\right. \\
& \left.+\left(S o C_{k}-S o C_{k-1}\right)^{2} Q_{y_{-} H 2}+\left(i_{H 2, k}^{b a t *}-i_{l_{-} p v, k}^{b a t}\right)^{2}\right]
\end{aligned}
$$

where $\mathrm{N}_{\mathrm{H} 2}$ is the prediction horizon, $\mathrm{Q}_{\mathrm{r}_{-} \mathrm{H} 2}$ and $\mathrm{Q}_{\mathrm{y} \_\mathrm{H} 2}$ are the weights of the cost function. SoC* is the State of Charge reference.

$\mathrm{Q}_{\mathrm{r}_{\_} \mathrm{H} 2}$ and $\mathrm{Q}_{\mathrm{y}_{-} \mathrm{H} 2}$ are used to fix the importance of the terms in the cost function. If $\mathrm{Q}_{\mathrm{r}_{-} \mathrm{H} 2}$ is lower than $\mathrm{Q}_{\mathrm{y}_{-} \mathrm{H} 2}$, the controller would not ensure the reference tracking, so the weights are chosen to stabilize the SoC at is reference. To keep the SoC in specific range SoCmin and SoCmax, the SoC reference depends on the current SoC value :

If the $\mathrm{SoC}$ is between the upper and lower bound, the

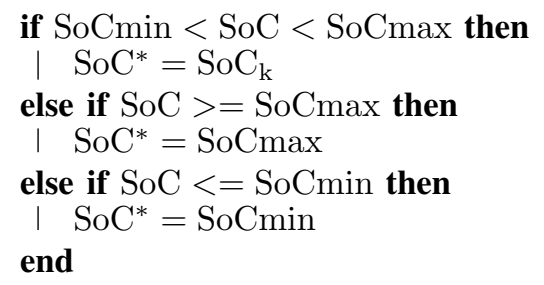

algorithm let the batteries charge and discharge depending on the energy need. If the battery SoC is lower than the lower bound, the FC charge the battery. If it's higher than the upper bound, the battery discharge by supply the electrolyzer.

\section{- Switch parameters}

$\mathrm{i}_{\mathrm{H} 2, \min }$ and $\mathrm{i}_{\mathrm{H} 2, \max }$ are considered to be equal to $\mathrm{i}_{\mathrm{El}, \min }$ and $\mathrm{i}_{\mathrm{FC}, \max }$ respectively, and $\mathrm{v}_{\mathrm{H} 2, \mathrm{k}}$ and $\Delta \mathrm{i}_{\mathrm{H} 2, \max }$ values depend on the $\mathrm{H} 2$ unit used, which depends on the sign of the $\mathrm{H} 2$ unit current :

$$
\begin{aligned}
& \text { if } \mathrm{i}_{\mathrm{H} 2, \mathrm{k}}^{\text {bat* }}>=0 \text { then } \\
& \begin{array}{l}
\mathrm{v}_{\mathrm{H} 2, \mathrm{k}}=\mathrm{v}_{\mathrm{fc}, \mathrm{k}}, \Delta \mathrm{i}_{\mathrm{H} 2, \max }=\Delta \mathrm{i}_{\mathrm{fc}, \max } \\
\mathrm{i}_{\mathrm{fc}}^{\text {bat* }}=\mathrm{i}_{\mathrm{H} 2}^{\text {bat* }}
\end{array} \\
& \text { else } \\
& \begin{array}{l}
\mathrm{v}_{\mathrm{H} 2, \mathrm{k}}^{\text {bat* }}=\mathrm{v}_{\mathrm{el}, \mathrm{k}}, \Delta \mathrm{i}_{\mathrm{H} 2, \max }=\Delta \mathrm{i}_{\mathrm{el}, \max } \\
\text { end }
\end{array}
\end{aligned}
$$

\section{Batteries controller}

- Equation and constraints

Battery stack aim is to maintain the DC bus voltage close to its reference. The discrete-time equation of the DC 
bus voltage dynamic is written (Equ. 16) to compute the DC bus voltage at each step time and minimize the cost function. To linearize the system equation, the current of each unit is written in the DC bus point of view with the power conservation assumption. The battery stack current reference seen by the bus $\mathrm{i}_{\mathrm{bat}, \mathrm{k}}^{\mathrm{b} *}$ is the control variable.

$$
v_{b, k+1}=v_{b, k}+\frac{T_{S_{b a t}}}{C_{b}}\left(i_{b a t, k}^{b *}+i_{H 2, k}^{b}-i_{l_{-} p v, k}\right)
$$

where $\mathrm{i}_{\text {bat }}^{\mathrm{b} *}$ is the battery stack current seen by the DC bus, $\mathrm{i}_{\mathrm{H} 2}^{\mathrm{b}}$ is the $\mathrm{H} 2$ unit current seen by the DC bus, $\mathrm{i}_{1 \text {-pv }}$ is the difference between load current and PV current seeing by the bus $\left(\mathrm{i}_{1-\mathrm{pv}}=\mathrm{i}_{1}-\mathrm{i}_{\mathrm{pv}}^{\mathrm{b}}\right), \mathrm{C}_{\mathrm{b}}$ is the capacitor DC bus, $\mathrm{v}_{\mathrm{b}}$ is the DC bus voltage. $T_{S_{b a t}}$ is the sample time of the DEMPC.

The maximum charge and discharge current is rewritten in the DC bus point of view with the power conservation assumption and is considered as a constraint in the DEMPC.

$$
\begin{gathered}
-i_{b a t, \min , k}^{b} \leq i_{b a t, k}^{b} \leq i_{b a t, \max , k}^{b} \\
i_{b a t, \min , k}^{b}=\frac{v_{b a t, k}}{v_{b, k}} i_{b a t, \min } \\
i_{b a t, \max , k}^{b}=\frac{v_{b a t, k}}{v_{b, k}} i_{b a t, \max }
\end{gathered}
$$

$\mathrm{v}_{\text {bat }}$ is the battery stack voltage.

- Cost function

To keep the DC bus voltage close to its reference, the cost function is written to minimize at each horizon step the error between $\mathrm{v}_{\mathrm{b}, \mathrm{k}}$ and $\mathrm{v}_{\mathrm{b}}^{*}$ (first term), the battery stack current seen by bus amplitude (second term) (Equ. 20).

$$
J\left(v_{b, k}\right)=\min _{i_{b a t}^{b}} \sum_{k=0}^{N_{b a t}}\left[\left(v_{b, k}-v_{b}^{*}\right)^{2} Q_{r_{-} b a t}+i_{b a t, k}^{b *}{ }^{2}\right]
$$

where $\mathrm{N}_{\text {bat }}$ is the prediction horizon, $\mathrm{Q}_{\mathrm{r}_{-} \text {bat }}$ is the weight of the cost function. $\mathrm{v}_{\mathrm{b}}^{*}$ is the $\mathrm{DC}$ bus voltage reference.

As for the $\mathrm{H} 2$ unit cost function, $\mathrm{Q}_{\mathrm{r}_{-} b a t}$ is used to fix the importance of the term in the cost function. If the $\mathrm{Q}_{\mathrm{r}_{-} \text {bat }}$ weight is too high, the controller will determine a to high value for $i_{\text {bat,k }}^{b}$ that will cause oscillations in this current between $\mathrm{i}_{\text {bat,min }}^{\mathrm{b}}$ and $\mathrm{i}_{\text {bat,max }}^{\mathrm{b}}$. So the value of $\mathrm{Q}_{\mathrm{r}-b a t}$ should be fixed to ensure stability in the battery stack current and to ensure the tracking reference.

\section{Kalman filter}

$i_{1}$ is an unmeasured current that need to be estimated. For the DEMPC, this current is seen like a perturbation, so if $\mathrm{f}=\mathrm{i}_{\mathrm{l}-\mathrm{pv}, \mathrm{k}}-\mathrm{i}_{\mathrm{H} 2, \mathrm{k}}^{\mathrm{b}}$ is considered, equ. 16 can be rewritten to equ. 21 with the hypothesis that $\dot{f}$ is nearly equal to zero and a suboptimal Kalman filter can be used to estimate $f$. $f$ can be re-injected in 16 and $i_{1-p v, k}=i_{\mathrm{H} 2, \mathrm{k}}^{b}+\mathrm{f}$.

$$
\left(\begin{array}{c}
v_{b, k+1} \\
f_{k+1}
\end{array}\right)=\left(\begin{array}{cc}
1 & \frac{-T_{S_{b a t}}}{C_{b}} \\
0 & 1
\end{array}\right)\left(\begin{array}{c}
v_{b, k} \\
f_{k}
\end{array}\right)+\left(\begin{array}{c}
\frac{-T_{S_{b a t}}}{C_{b}} \\
0
\end{array}\right) i_{b a t, k}^{b}
$$
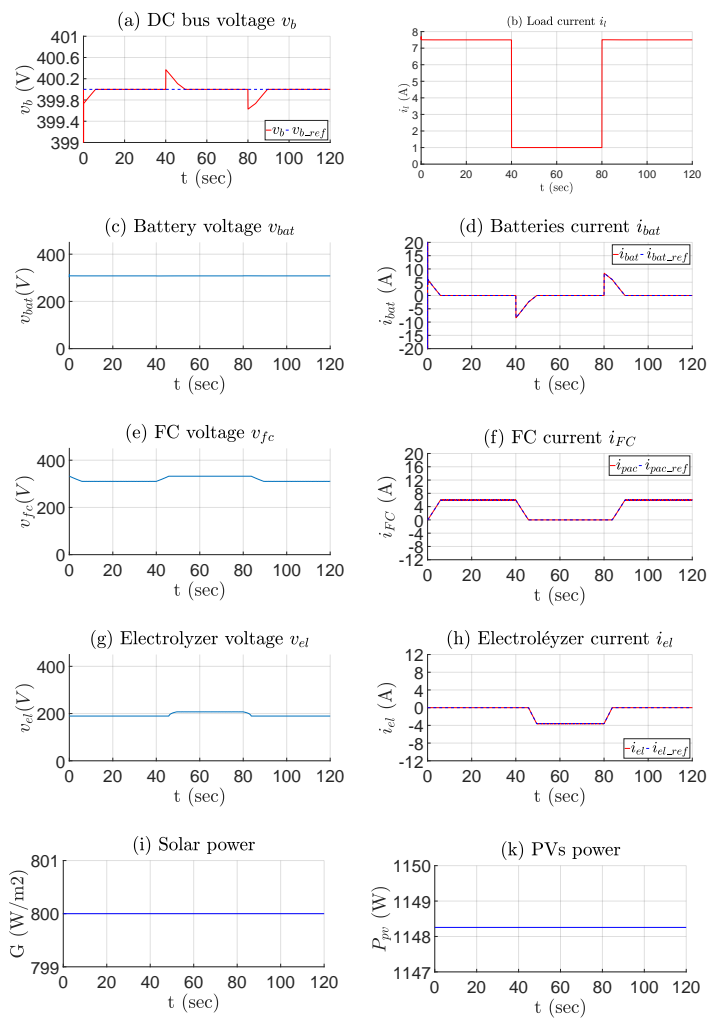

Fig. 4. Normal condition : DC bus voltage (a), Load current (b), Battery stack voltage (c) and current (d), Fuel Cell voltage (e) and current (f), Electrolyzer voltage (g) and current (h), Solar radiation (i) PV power (j)

\section{E. Current references}

The current references of each unit is determined with the power conservation hypothesis :

$$
\begin{aligned}
& i_{e l}^{*}=\frac{v_{b a t}}{v_{e l}} i_{e l}^{b a t *} ; i_{f c}^{*}=\frac{v_{b a t}}{V_{f c}} i_{f c}^{b a t *} \\
& i_{b a t}^{*}=\frac{v_{b}}{v_{b a t}} i_{b a t}^{b *}
\end{aligned}
$$

\section{RESULTS}

The performance of the controller is tested in 4 operating conditions : normal condition, FC disconnection, Electrolyzer disconnection and Solar radiation loss. The Matlab/Simulink environment is used to perform the simulation with a step time $\mathrm{h}=250 \mu \mathrm{s}$. Weigth, step time and horizon length of the MPC is detailed in Appendix.

- Case 1 : Normal condition (Fig. 4)

At constant solar radiation (Fig. 4.i) and constant temperature at $25^{\circ} \mathrm{C}$, small change variation can be observed in the DC bus voltage (Fig. 4.a) when the load suddenly varies (Fig. 4.b). The battery stack controller reacts immediately (Fig. 4.d) to bring the DC voltage at its reference. Moreover, the FC and the electrolyzer currents (Fig. 4.f and 4.h) increase or decrease progressively according to the ramp rate current limitation to bring the battery stack current to 0 in order to limit SoC variation. 

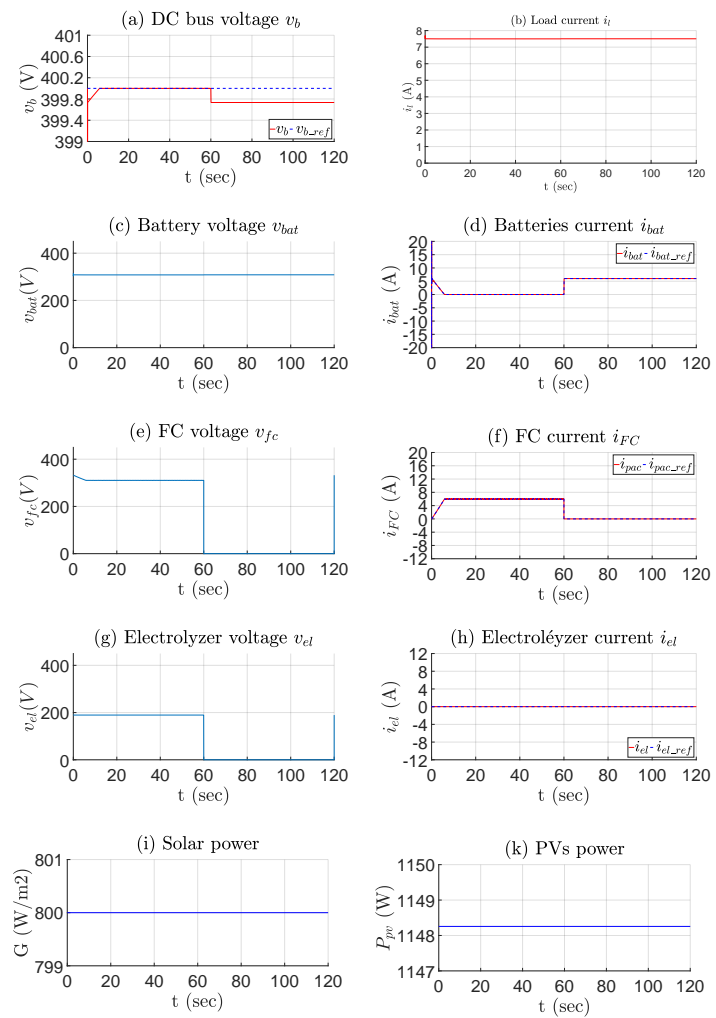

Fig. 5. FC disconnection : DC bus voltage (a), Load current (b), Battery stack voltage (c) and current (d), Fuel Cell voltage (e) and current (f), Electrolyzer voltage (g) and current (h), Solar radiation (i), PV power (j)

- Case 2 : FC disconnection (Fig. 5)

In the same weather conditions, when the PV power (Fig. 5.j) is lower than the load power (Fig. 5.a \& 5.b), the FC provides the load according to its response time. At $60 \mathrm{sec}$, the FC is disconnected to the DC bus for some reason (fault, irreversible degradation, etc.), the battery stack react and can provide the load according to the stack storage capacity.

\section{- Case 3 : Electrolyseur disconnection (Fig. 6)}

When the PV power (Fig. 6.j) is higher than the load power (Fig. 6.a \& 6.b), the extra power is provided to the electrolyzer according to its response time. In the same way as the $\mathrm{FC}$, at $60 \mathrm{sec}$ the electrolyzer is disconnected to the DC bus for some reason (fault, irreversible degradation, etc.), the extra power is provided to the battery to maintain the DC voltage at its reference.

- Case 4 : Solar radiation loss (Fig. 7)

When the weather conditions suddenly change, the PV power (Fig. 7.j) can decrease or increase roughly. This causes an instantaneously variation in the DC bus current. The battery stack react immediately to bring the DC bus voltage at its reference and the FC current increases progressively according to its response time to bring the battery stack current to 0 and limite the SoC variation.
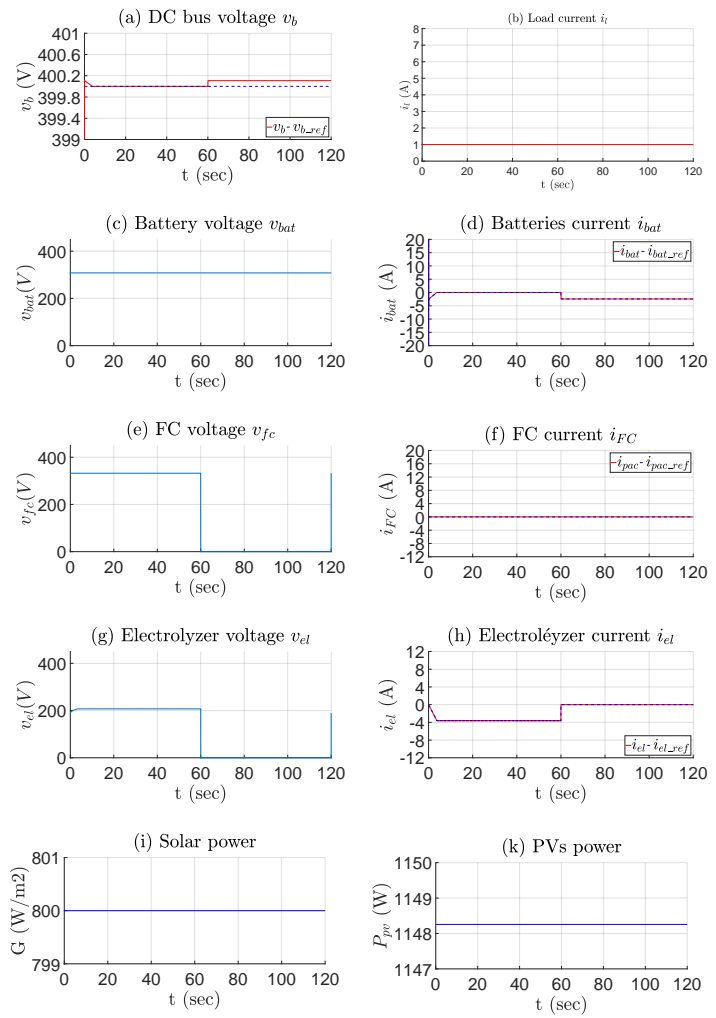

Fig. 6. Electrolyseur disconnection : DC bus voltage (a), Load current (b), Battery stack voltage (c) and current (d), Fuel Cell voltage (e) and current (f), Electrolyzer voltage (g) and current (h), Solar radiation (i), PV power (j)

\section{CONCLUSIONS AND FUTURE WORKS}

\section{A. Conclusions}

This paper presents an Energy Management System (EMS) for an hybrid system in a Micro Grid with photovoltaic panel, fuel cell, electrolyzer and battery. The units current references are computed with a Distributed Explicit Model Predictive Control (DEMPC) implemented with Yalmip, Multi Parametric Toolbox 3 and Cplex solver. The simulation results show the good performance of the EMS in standard conditions, and when an unexpected event appears (fault, irreversible degradation, weather change, etc.).

\section{B. Future Works}

In perspective, a real-time test in a Hardware-In-theLoop test bench is under study to demonstrate the EMS performance in real operating conditions. Also, a start/stop optimization for the FC and the electrolyzer taking into account the time up/down, the FC and electrolyzer minimal operating current and the load/weather prediction is in under study to improve their health state on the long term.

\section{ACKNOWLEDGMENTS}

An appreciation is addressed to the ERDF ('European Regional Development Fund"). This project is supported by the Region Council of La Réunion. 

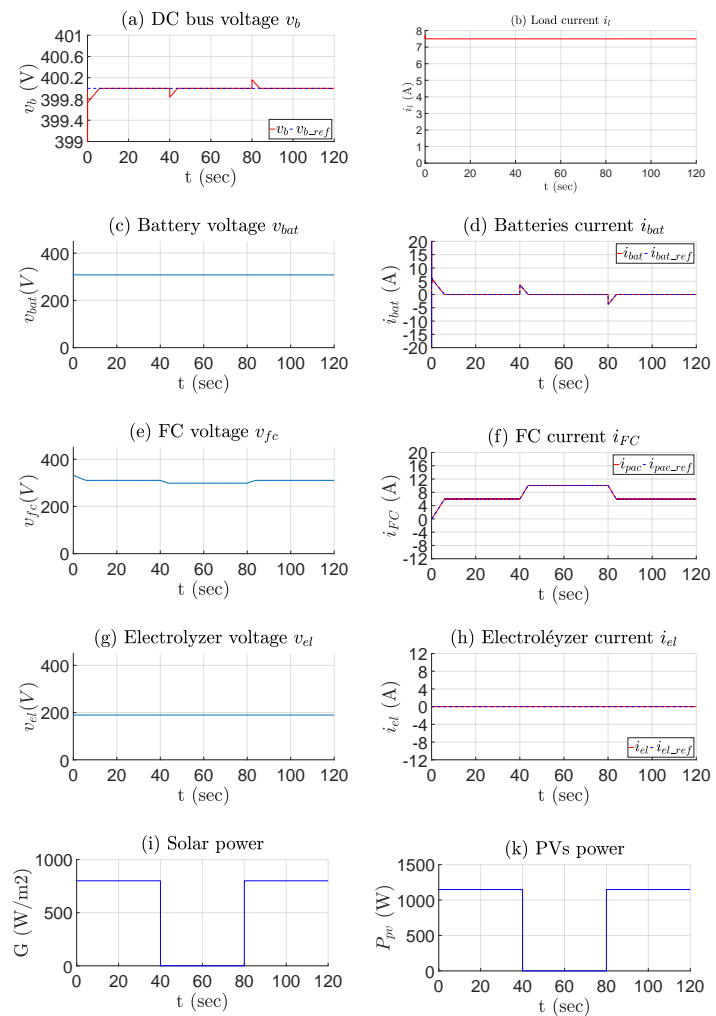

Fig. 7. Solar radiation loss : DC bus voltage (a), Load current (b), Battery stack voltage (c) and current (d), Fuel Cell voltage (e) and current (f), Electrolyzer voltage (g) and current (h), Solar radiation (i), PV power (j)

\section{APPENDIX}

\section{SYSTEM PARAMETERS}

\begin{tabular}{|c|c|c|c|}
\hline \multicolumn{4}{|c|}{ PVs $\left(1000 W / m^{2}\right)$} \\
\hline Maximum power & $180 \mathrm{~W}$ & In parallel & 2 \\
\hline Voltage at maximum power & $36.2 \mathrm{~V}$ & In series & 6 \\
\hline Current at maximum power & $5 \mathrm{~A}$ & & \\
\hline \multicolumn{2}{|l|}{ Electrolyzer } & \multicolumn{2}{|l|}{ Fuel Cell } \\
\hline Maximum $\mathrm{H} 2$ production & $1 \mathrm{Nm}^{3} / \mathrm{h}$ & Maximum power & $1200 \mathrm{~W}$ \\
\hline Rated voltage & $43 \mathrm{~V}$ & Rated voltage & $26 \mathrm{~V}$ \\
\hline Rated current & $120 \mathrm{~A}$ & Rated current & $46 \mathrm{~A}$ \\
\hline In parallel & 1 & In parallel & 1 \\
\hline In series & 1 & In series & 2 \\
\hline Cell number & 22 & Cell number & 47 \\
\hline \multicolumn{4}{|c|}{ DC bus } \\
\hline$C_{b}$ & $0.15 \mathrm{~F}$ & DC bus voltage ref. & $400 \mathrm{~V}$ \\
\hline \multicolumn{4}{|c|}{ MPC } \\
\hline$T_{S_{b a t}}$ & $500 \mu s$ & $Q_{r_{-} H 2}$ & 800 \\
\hline$T_{S_{H 2}}$ & $2 \mathrm{~ms}$ & $Q_{y_{\_} H 2}$ & 800 \\
\hline$N_{\text {bat }}$ & 5 & $Q_{r_{-} b a t}$ & 1000 \\
\hline$N_{H 2}$ & 3 & & \\
\hline
\end{tabular}

\section{REFERENCES}

[1] M. Behrendt, N. Bajcinca, F. Zenith, and U. Krewer, "Model predictive control of a hybrid fuel cell \& battery power system," vol. 45, no. 15, pp. 131-136. [Online]. Available: http://linkinghub.elsevier.com/retrieve/pii/S1474667016304311
[2] M. Hilairet, M. Ghanes, O. Béthoux, V. Tanasa, J.-P Barbot, and D. Normand-Cyrot, "A passivity - based controller for coordination of converters in a fuel cell system," vol. 21, no. 8, pp. 1097-1109. [Online]. Available: https://www.sciencedirect.com/science/article/pii/S0967066113000701

[3] M.-Y. Ayad, S. Pierfederici, S. Raël, and B. Davat, "Voltage regulated hybrid DC power source using supercapacitors as energy storage device," vol. 48, no. 7, pp. 2196-2202. [Online]. Available: http://www.sciencedirect.com/science/article/pii/S0196890407000076

[4] C. Darras, S. Sailler, C. Thibault, M. Muselli, P. Poggi, J. C. Hoguet, S. Melscoet, E. Pinton, S. Grehant, F. Gailly, C. Turpin, S. Astier, and G. Fontès, "Sizing of photovoltaic system coupled with hydrogen/oxygen storage based on the ORIENTE model," vol. 35, no. 8, pp. 3322-3332. [Online]. Available: http://www.sciencedirect.com/science/article/pii/S036031991000131X

[5] M. Amin, A. Rasheed, A. A. Raja, A. Lateef, S. Khalid, and B. Khan, "Smart-Grid Based Real-Time Load Management Methodology for Power Deficient Systems," pp. 431 - 437.

[6] T. D. Khoa, L. T. Dos Santos, M. Sechilariu, and F. Locment, "Load shedding and restoration real-time optimization for DC microgrid power balancing," in Energy Conference (ENERGYCON), 2016 IEEE International. IEEE.

[7] T. Zhang, P. Wang, H. Chen, and P. Pei, "A review of automotive proton exchange membrane fuel cell degradation under start-stop operating condition," vol. 223, pp. 249-262. [Online]. Available: https://linkinghub.elsevier.com/retrieve/pii/S030626191830607X

[8] T. Fletcher, R. Thring, and M. Watkinson, "An Energy Management Strategy to concurrently optimise fuel consumption \& PEM fuel cell lifetime in a hybrid vehicle," vol. 41, no. 46, pp. 21503-21515. [Online]. Available: https://linkinghub.elsevier.com/retrieve/pii/S0360319916325435

[9] A. Godula Jopek and D. Stolten, Hydrogen Production: By Electrolysis. Agata Godula-Jopek. [Online]. Available: https://www.wiley.com/

[10] M. Carmo, D. L. Fritz, J. Mergel, and D. Stolten, "A comprehensive review on PEM water electrolysis," vol. 38, no. 12, pp. 4901-4934. [Online]. Available: http://linkinghub.elsevier.com/retrieve/pii/S0360319913002607

[11] E. Dijoux, N. Y. Steiner, M. Benne, M.-C. Péra, and B. G. Pérez, "A review of fault tolerant control strategies applied to proton exchange membrane fuel cell systems," vol. 359, pp. 119-133. [Online]. Available: https://linkinghub.elsevier.com/retrieve/pii/S0378775317306997

[12] C. Lebreton, M. Benne, C. Damour, N. Yousfi-Steiner, B. Grondin-Perez, D. Hissel, and J.-P. Chabriat, "Fault Tolerant Control Strategy applied to PEMFC water management," vol. 40, no. 33, pp. 10636-10646. [Online]. Available: https://linkinghub.elsevier.com/retrieve/pii/S0360319915016006

[13] J. Hare, X. Shi, S. Gupta, and A. Bazzi, "Fault diagnostics in smart micro-grids: A survey," vol. 60, pp. 1114-1124. [Online]. Available: https://linkinghub.elsevier.com/retrieve/pii/S1364032116001775

[14] Xingyu YAN, "Gestion énergétique sous incertitude : Application à la planification et à l'allocation de réserve dans un micro réseau électrique urbain comportant des générateurs photovoltaïques actifs et du stockage," Ph.D. dissertation. [Online]. Available: http://12ep.univ-lille1.fr/?p=4366

[15] P. Dieguez, A. Ursua, P. Sanchis, C. Sopena, E. Guelbenzu, and L. Gandia, "Thermal performance of a commercial alkaline water electrolyzer: Experimental study and mathematical modeling," vol. 33, no. 24, pp. 7338-7354. [Online]. Available: http://linkinghub.elsevier.com/retrieve/pii/S0360319908012093

[16] M. Chen and G. Rincon-Mora, "Accurate Electrical Battery Model Capable of Predicting Runtime and I-V Performance," vol. 21, no. 2, pp. 504-511. [Online]. Available: http://ieeexplore.ieee.org/document/1634598/

[17] J. Lofberg, "YALMIP : A toolbox for modeling and optimization in MATLAB," in In Proceedings of the CACSD Conference. [Online]. Available: https://yalmip.github.io/

[18] M. Kvasnica, J. Holaza, B. Takács, and D. Ingole, "Design and verification of low-complexity explicit MPC controllers in MPT3," in 2015 European Control Conference (ECC). 